\title{
AVALIAÇÃO AUDIOLÓGICA NA DOENÇA MITOCONDRIAL: RELATO DE DOIS CASOS
}

\section{Audiological evaluation in mitochondrial disease: two case report}

\author{
Marcela Rosana Maia da Silveira ${ }^{(1)}$, Daniela Gil (2)
}

\begin{abstract}
RESUMO
Tema: audição e mitocondriopatia. Procedimentos: este relato de caso teve como objetivo descrever os resultados da avaliação audiológica de duas crianças atendidas no ambulatório de audiologia clínica da Universidade Federal de São Paulo - Escola Paulista de Medicina (UNIFESP/EPM), com diagnóstico de doença mitocondrial, correlacionando os achados desta avaliação com a fisiopatologia subjacente. As crianças deste estudo, filhas de pais consangüíneos, foram encaminhadas para o ambulatório de audiologia clínica da UNIFESP-EPM pelo ambulatório de doenças metabólicas da mesma instituição em março de 2006 para realizar avaliação audiológica completa. As crianças foram submetidas à audiometria tonal, audiometria vocal, observação comportamental, medidas da imitância acústica e emissões otoacústicas. Resultados: as avaliações comportamental e fisiológica revelaram que as crianças apresentam deficiência auditiva neurossensorial de grau leve a moderadamente severo e presença de sobressalto com ausência de habituação, indicando assim, comprometimento auditivo central. Conclusão: estes relatos de casos ressaltam a importância de ser considerada a associação entre os fatores de risco para deficiência auditiva no planejamento da reabilitação dos pacientes.
\end{abstract}

DESCRITORES: DNA Mitocondrial; Perda Auditiva Neurossensorial; Congênito

\section{INTRODUÇÃO}

As doenças mitocondriais, primeiramente descritas por Luft et al ${ }^{1}$, ocorrem devido às mutações herdadas ou espontâneas do DNA (ácido desoxirribonucléico) mitocondrial ou DNA nuclear. A mitocôndria é a principal fonte de energia da célula, e tem a função de transformar a energia química dos metabólitos encontrados no citoplasma em energia que seja de fácil acesso a mesma, sendo uma de suas principais funções, a síntese de ATP (adenosina tri-fosfato) por fosforilação oxidativa.

Já a relação entre doença mitocondrial e deficiência auditiva foi estabelecida por Petty et al ${ }^{2}$, quando foi descrito o caso de um paciente com miopatia mitocondrial e deficiência auditiva. A partir daí, outros estudos apresentaram a deficiência auditiva

(1) Fonoaudióloga; Especializanda em Distúrbios da Comunicação Humana - Módulo II pela Universidade Federal de São Paulo.

(2) Fonoaudióloga; Professora Adjunto da Disciplina de Distúrbios da Audição do Departamento de Fonoaudiologia da Universidade Federal de São Paulo; Doutora em Distúrbios da Comunicação Humana pela Universidade Federal de São Paulo. associada ao quadro de alterações mitocondriais, como surdez sindrômica e surdez não-sindrômica ${ }^{2-4}$. Quando a perda auditiva de origem mitocondrial está relacionada a um quadro múltiplo é chamada de sindrômica e quando a surdez é o único sintoma, diz-se que é do tipo não-sindrômico 2,5 .

A incidência de deficiência auditiva de origem mitocondrial corresponde a aproximadamente 0,5 a $1,0 \%$ de todas as deficiências auditivas de origem genética, é do tipo neurossensorial, bilateral, progressiva e simétrica. Já o grau do comprometimento auditivo é variável ${ }^{2,5}$.

Baseado nestas constatações, o objetivo deste relato de caso é descrever os resultados da avaliação audiológica de duas crianças atendidas no ambulatório de audiologia clínica da Universidade Federal de São Paulo (UNIFESP-EPM) com diagnóstico de doença mitocondrial, procurando relacionar os achados desta avaliação com a fisiopatologia da doença subjacente.

\section{APRESENTAÇÃO DO CASO}

M.S.B., oito anos, sexo masculino (caso 1) e M.S.B., seis anos, sexo feminino (caso 2), irmãos, 
foram encaminhadas para o ambulatório de audiologia clínica da UNIFESP-EPM pelo ambulatório de doenças metabólicas da mesma instituição em março de 2006 para realizar avaliação audiológica completa. No entanto, os pais não referiram queixas quanto à audição.

Os pacientes foram submetidos a anamnese audiológica, audiometria com reforço visual realizada através de condicionamento estímulo-resposta-reforço visual, conforme os critérios propostos por Suzuki e Ogiba ${ }^{6}$. Utilizou-se um audiômetro pediátrico modelo PA-2 da Interacoustics, que produz tons puros modulados warble nas freqüências de 500, 1000, 2000 e $4000 \mathrm{~Hz}$ a 80, 60, 40 e 20 dB NA, a partir dos quais buscou-se a mínima intensidade que provocou resposta de localização. As respostas obtidas na avaliação comportamental a estímulos acústicos foram classificadas segundo critérios de Azevedo ${ }^{7}$, e o padrão de normalidade da observação comportamental a estímulos sonoros obedeceu aos critérios propostos por Azevedo ${ }^{8}$. A pesquisa do limiar de detecção de voz foi realizada em cabina acústica com audiômetro modelo MA-41 marca MAICO. Para identificação de comprometimento de orelha externa e/ou média foram realizadas pela pesquisadora a meatoscopia, com o otoscópio de marca Welch Allyn, o registro de curva timpanométrica e pesquisa do limiar de reflexo acústico contralateral nas freqüências de 500, 1000,2000 e $4000 \mathrm{~Hz}$, em função da utilização do equipamento AZ-7.

A avaliação fisiológica por emissões otoacústicas evocadas transitórias e produto de distorção foi realizada com o equipamento ILO-92. Para as emissões otoacústicas evocadas transitórias, foi utilizado o modo quickscreen, no qual são apresentados 260 cliques não lineares com intensidade entre 75 e $85 \mathrm{~dB}$ pico equivalente. São pesquisadas as seguintes bandas de freqüência: 1000, 1500, 2000 e $4000 \mathrm{~Hz}$. Para considerar respostas presentes, deve-se obter respostas com amplitude de no mínimo $6 \mathrm{~dB}$ em todas as bandas de freqüências; reprodutibilidade maior ou igual a $50 \%$ e estabilidade da sonda maior ou igual a $70 \%$. Já para as emissões otoacústicas produto de distorção, utilizamos o modo DP-Gram do equipamento, sendo $\mathrm{F} 1=1000 \mathrm{~Hz}$ e F2 $=1200 \mathrm{~Hz}$ com intensidade de $75 \mathrm{~dB}$ pico equivalente. Para serem considerados presentes, deve-se observar uma resposta com diferença mínima de $3 \mathrm{~dB}$ em relação ao ruído, nas freqüências de 1000, 2000, $3000,4000,5000$ e $6000 \mathrm{~Hz}$.

Este relato de caso foi analisado e aprovado pelo Comitê de Ética em Pesquisa da Universidade Federal de São Paulo (UNIFESP/EPM) com o protocolo de no 1854/06.

Os resultados foram submetidos a uma análise descritiva.

\section{RESULTADOS}

Anamnese: M.S.B.,8 anos, sexo masculino (caso 1) e M.S.B., 6 anos, sexo feminino (caso 2). Pais primos de primeiro grau, não referem casos de doença mitocondrial e/ou deficiência auditiva na família. Mãe relata que as gestações transcorreram normalmente, tendo realizado o pré-natal desde o início, não apresentando intercorrências pré, peri ou pós-natais. Ambas as crianças nasceram a termo e adequadas para a idade gestacional. Porém, antes de M. (caso 1) completar 1 ano de idade, os médicos iniciaram a investigação do caso devido ao atraso no desenvolvimento global. Somente aos 6 anos de idade do caso 1, quando o caso 2 já encontrava-se com 4 anos de idade, a hipótese de doença mitocondrial foi proposta e em seguida confirmada.

Os pais relataram que os filhos assustam-se com sons de forte intensidade, no entanto não apresentam queixas quanto à audição de seus filhos.

Os menores apresentam alterações motoras significativas (não andam), atrofia de membros superiores e inferiores, alterações fenotípicas relacionadas à face e sialorréia intensa.

Avaliação audiológica: Na Figura 1, estão descritos os níveis mínimos de resposta (NMR) para o audiômetro pediátrico, para ambos os casos.

$\mathrm{Na}$ Figura 2, estão descritos os resultados da avaliação comportamental frente a sons instrumentais, segundo os critérios propostos por Azevedo ${ }^{8}$.

O limiar de detecção de voz, em cabina acústica do caso 1 pesquisado em campo livre, foi de $55 \mathrm{~dB}$ $\mathrm{NA}$; já do caso 2, foi de $45 \mathrm{~dB}$ NA em ambas as orelhas com fones supra-aurais.

\begin{tabular}{|lcccccccc|}
\hline \multirow{2}{*}{ NMR } & \multicolumn{2}{c}{$500 \mathrm{~Hz}$} & \multicolumn{2}{c}{$1000 \mathrm{~Hz}$} & \multicolumn{2}{c|}{$2000 \mathrm{~Hz}$} & \multicolumn{2}{c|}{$4000 \mathrm{~Hz}$} \\
\cline { 2 - 10 } & OD & OE & OD & OE & OD & OE & OD & OE \\
\hline Caso 1 (dB NA) & 80 & 60 & 60 & 60 & 60 & 60 & 60 & 60 \\
Caso 2 (dB NA) & 60 & 40 & 60 & 40 & 60 & 60 & 60 & 40 \\
\hline
\end{tabular}

Legenda: $\mathrm{OD}=$ orelha direita; $\mathrm{OE}=$ orelha esquerda; $\mathrm{dB} \mathrm{NA}=$ decibéis em nível de audição; $\mathrm{NMR}=$ nível mínimo de resposta.

Figura 1 - Níveis mínimos de resposta para o audiômetro pediátrico 


\begin{tabular}{|lccccc|}
\hline $\begin{array}{l}\text { Observação } \\
\text { comportamental }\end{array}$ & $\begin{array}{c}\text { LL } \\
(50-70 \mathrm{~dB} \\
\text { NPS }) \\
\text { D E }\end{array}$ & $\begin{array}{c}\text { LB } \\
(70-90 \mathrm{~dB} \\
\text { NPS })\end{array}$ & $\begin{array}{c}\text { LC } \\
(70-90 \mathrm{~dB} \\
\text { NPS })\end{array}$ & $\begin{array}{c}\text { RCP } \\
(90-100 \mathrm{~dB} \\
\text { NPS })\end{array}$ & $\begin{array}{c}\text { Sobressalto } \\
\left(\begin{array}{c}\text { Sem habituação) } \\
(90-100 \mathrm{~dB} \\
\text { NPS })\end{array}\right.\end{array}$ \\
\hline Caso 1 & $\mathrm{XX}$ & $\mathrm{D}$ & $\mathrm{D}$ & $\mathrm{X}$ & $\mathrm{X}$ \\
\hline Caso 2 & $\mathrm{XX}$ & $\mathrm{D}$ & $\mathrm{I}$ & $\mathrm{X}$ & $\mathrm{X}$ \\
\hline
\end{tabular}

Legenda: $\mathrm{LL}=$ Localização lateral; $\mathrm{LB}=$ Localização para baixo; $\mathrm{LC}=$ Localização para cima; $\mathrm{RCP}=$ Reflexo cócleo-palpebral; $\mathrm{X}=$ Presente; $\mathrm{D}=$ Direta; $\mathrm{I}=$ Indireta .

Figura 2 - Resultados da avaliação comportamental frente a sons instrumentais

As medidas de imitância acústica revelaram curvas timpanométricas do tipo $\mathrm{A}$ e reflexos acústicos contralaterais presentes com recrutamento, ou seja, diferença entre o limiar auditivo tonal e o limiar do reflexo acústico menor do que $60 \mathrm{~dB} \mathrm{NA}$, bilateralmente, em ambos os casos ${ }^{9}$.

As emissões otoacústicas evocadas transitórias mostraram-se ausentes bilateralmente em ambas as crianças e emissões otoacústicas produto de distorção presentes apenas na orelha esquerda do caso 2, em todas as freqüências.

Como demonstrado, tanto pela avaliação comportamental como fisiológica, verifica-se que a criança do caso 1 apresentou deficiência auditiva neurossensorial de grau moderado a moderadamente severo e a do caso 2 deficiência auditiva neurossensorial de grau leve a moderado. A presença de sobressalto com ausência de habituação a estímulos repetidos indica comprometimento auditivo central ${ }^{10}$.

\section{DISCUSSÃO}

Neste tópico serão comentados os achados audiológicos bem como demais características da doença mitocondrial dos casos estudados, comparando-os com outros estudos da literatura especializada.

São indicadores de risco para deficiência auditiva: antecedentes familiares de deficiência auditiva neurossensorial hereditária, infecções maternas, infecções congênitas (rubéola, sífilis, citomegalovírus, herpes e toxoplasmose), malformações craniofaciais, incluindo as de pavilhão auricular e meato acústico externo, peso ao nascimento abaixo de $1.500 \mathrm{~g}$, hiperbilirrubinemia - exsangüineotransfusão, medicação ototóxica (aminoglicosídeos, associação com diuréticos, agentes quimioterápicos), meningite bacteriana, índice de Apgar de 0 a 4 no primeiro minuto ou de 0 a 6 no quinto minuto de vida, ventilação mecânica por mais de cinco dias, síndromes diversas, alcoolismo materno, otite média recorrente ou persistente por mais de três meses, suspeita dos familiares de atraso do desenvolvi- mento da fala linguagem e audição, permanência na unidade de terapia intensiva (UTI) por mais de 48 horas, traumatismo cranioencefálico com perda de consciência ou fratura craniana ${ }^{11,12}$.

Além destes, também são considerados como indicadores de risco para a deficiência auditiva, consangüinidade, criança pequena para a idade gestacional (PIG), uso de drogas psicotrópicas na gestação, hemorragia ventricular, convulsões neonatais, permanência na incubadora por mais de sete dias, Síndrome da Imuno Deficiência Adquirida (SIDA ou AIDS) materna e asfixia ${ }^{13}$.

Como visto, a deficiência auditiva pode ser decorrente de várias etiologias, dentre elas a de origem genética que é responsável por deficiências auditivas congênitas e adquiridas ${ }^{5}$. Uma série de alterações do DNA mitocondrial, segundo alguns estudos, estão associadas ao comprometimento auditivo ${ }^{4,14,15}$.

O DNA mitocondrial tem suas próprias características possuindo um sistema independente de transcrição, translação e replicação do seu genoma; e tem herança materna, uma vez que as mitocôndrias presentes no espermatozóide encontram-se na cauda deste e, portanto, não penetram o óvulo durante a fecundação. Assim sendo, as mitocôndrias presentes no embrião são herdadas exclusivamente da mãe ${ }^{16}$.

Na maioria dos trabalhos revisados encontramse relato de deficiência auditiva como manifestação das alterações mitocondriais ${ }^{1,5,17-19}$. Além disto, foi descoberta uma mutação do DNA mitocondrial comum a todos os pacientes - substituição do nucleotídeo adenina pelo guanina no lócus 3243 do gene tRNA codificador de uma leucina [gene tRNAleu] - a qual tem como uma de suas características clínicas a deficiência auditiva neurossensorial, inicialmente nas freqüências altas, de caráter progressivo e com recrutamento, sugerindo uma alteração puramente coclear ${ }^{20}$.

Conforme citado no tópico de resultados, os pacientes deste estudo apresentaram deficiência neurossensorial de grau leve a moderadamente severo, demonstrando comprometimento coclear, 
evidenciado pelos resultados às emissões otoacústicas e presença de recrutamento.

As alterações auditivas decorrentes do comprometimento anatomofuncional do Sistema Nervoso Central interferem diretamente com a habilidade de processamento dos estímulos acústicos e, por conseqüência, o desenvolvimento da linguagem ${ }^{13}$.

Existem relatos na literatura que citam o quadro clínico da doença mitocondrial como polimorfo, incluindo sinais de comprometimento muscular, cardíaco, auditivo, visual e dos sistemas endócrino e nervoso ${ }^{18}$.

Já em relação ao fenótipo, as alterações dependem da gravidade da mutação e da necessidade de produção de energia do órgão envolvido ${ }^{16}$. No entanto, sabe-se que uma mutação mitocondrial idêntica pode levar a fenótipos completamente diferentes ${ }^{3,4}$.

Além da deficiência auditiva, as crianças deste estudo apresentaram alterações fenotípicas relacionadas à face e sialorréia intensa. Frente às alterações fenotípicas apresentadas pelas crianças podemos hipotetizar que a mutação envolvida seja severa. As doenças mitocondriais podem ocorrer por herança autossômica recessiva ou por herança mitocondrial. As mitocôndrias são todas maternas, porque o espermatozóide quando penetra o óvulo só entra com os cromossomos, a célula em que os seres humanos se desenvolvem é materna com todas as suas organelas, inclusive a mitocôndria e seu DNA. Se existe um gene deficiente no DNA mitocondrial a mãe terá o risco de praticamente $100 \%$ a cada gestação de ter um filho ou filha com a doença ${ }^{21}$.

Esta afirmação justificaria a recorrência da doença nos casos relatados, uma vez que os pacientes são irmãos. Tal dado também se torna importante para o aconselhamento genético de família com crianças que apresentam doenças mitocondriais.

\section{CONCLUSÃO}

É possível concluir que a associação entre fatores de risco para deficiência auditiva (consangüinidade e doença mitocondrial) nos casos apresentados resultou em perda auditiva neurossensorial com indicador de perda auditiva central.

\begin{abstract}
Background: hearing and mitochondriopathy. Procedure: this case report aims at describing audiological evaluation results of two children diagnosed with mitochondrial disease referred to Clinical Audiology Out-patient Clinic of UNIFESP/EPM. Children were referred to audiology department from metabolic diseases out-patient clinic of UNIFESP. Both have undergone pure tone audiometry, behavioral observation, immittance measures and otoacoustic emissions. Results: either behavioral or physiological evaluations revealed abnormal results evidencing mild to moderate-to-severe sensorineural hearing loss and presence of startle reflex without habituation, indicating central auditory involvement. Conclusion: these case reports reinforce the importance of considering the association of risk factor for hearing loss in the rehabilitation planning of these patients.
\end{abstract}

KEYWORDS: DNA, Mitochondrial; Hearing Loss, Sensorineural; Congenital

\section{REFERÊNCIAS}

1. Luft R, Ikkos D, Palmieri G, Ernster L, Afzelius B. A case of severe hypermetabolism of nonthyroid origin with a defect in the maintenance of mitochondrial respiratory control: a correlated clinical, biochemical, and morphological study. J Clin Invest. 1962; 41(9):1776-804.

2. Petty RKH, Harding AE, Morgan-Hughes JA. The clinical features of mitochondrial myopathy. Brain. 1986; 109(5):915-38.
3. Swift AC, Singh SD. Hearing impairment and the Kearns-Sayre syndrome. J Laryngol Otol. 1988; 102:626-7.

4. Jaber L, Shohat $M, B u X$, Fischel-Ghodsian N, Yang HY, Wang SJ, et al. Sensorineural deafness inherited as a tissue specific mitochondrial disorder. J Med Genet. 1992; 29:86-90.

5. Carvalho MFP, Ribeiro FAQ. As deficiências auditivas relacionadas às alterações do DNA mitocondrial. Rev Bras Otorrinolaringol. 2002; 68(2):268-75. 
6. Suzuki T, Ogiba Y. Conditioned orientation reflex audiometry. Arch Otolaryngol. 1961; 74:192-8.

7. Azevedo MF. Avaliação e acompanhamento audiológico de neonatos de risco. Acta Awho. 1991; 10(3):107-16.

8. Azevedo MF. Desenvolvimento auditivo de crianças normais e de alto risco: estudo comparativo das respostas comportamentais a estímulos sonoros [tese]. São Paulo (SP): Universidade Federal de São Paulo; 1993.

9. Jerger J. Clinical experience with impedance audiometry. Arch Otolaryngol. 1970; 92:311-24.

10. Andrade AN, Amador HC, Gil D, Azevedo MF. Indicadores de alteração auditiva central em uma população ambulatorial. Fono Atual. 2005; 8(34):25-33.

11. American Academy of Pediatrics. Joint Committee on Infant Hearing: 1994 Position Statement. Pediatrics. 1995; 95(1):152-6.

12. Joint Committee on Infant Hearing; American Academy of Audiology; American Academy of Pediatrics. American Speech-Language-Hearing Association; Directors of Speech and Hearing Programs in State Health and Welfare Agencies. Year 2000 position statement: principles and guidelines for early hearing detection and intervention programs. Pediatrics. 2000; 106(4):798-817.

13. Azevedo MF. Avaliação audiológica no primeiro ano de vida. In: Lopes OC. Tratado de fonoaudiologia. São Paulo: Roca; 1997. p. 239-63.
14. Oshima T, Ueda N, Ikeda K, Abe K, Takasaka $\mathrm{T}$. Bilateral sensorineural hearing loss associated with the point mutation in mitochondrial genome. Laryngoscope. 1996; 106(1Pt1):43-8.

15. EnsinkRJH, CampGV, CremersRJ. Mitochondrial inherited hearing loss. Clin Otolaryngol. 1998; 23(1):3-8.

16. Wallace DC. Diseases of the mitochondrial DNA. Annu Rev Biochem. 1992; 61:1175-212.

17. Seidman MD, Bai U, Khan MJ, Murphy MJ,Quirk WS, Castora FL, et al. Association of mitochondrial DNA deletions and coclear pathology: a molecular biologic tool. Laryngoscope. 1996; 106(6):777-83.

18. Clarke JTR. A clinical guide to inherited metabolic diseases. Cambridge: Cambridge University Press; 1996.

19. Schapira AH. Mitochondrial disease. Lancet. 2006; 368(9529):70-82.

20. Van Den Ouweland JMW, Lemkes HHPJ, Ruitenbeek W, Sandkuijl LA, De Vijlder MF, Struyvenberg PA, et al. Mutation in mitochondrial tRNAleu(uur) gene in a large pedigree with maternally transmitted type II diabetes mellitus and deafness. Nat Genet. 1992; 1:368-71.

21. Centro de referência em erros inatos do metabolismo. [online] Disponível em: URL:http:// www.unifesp.br/centros/creim/tiposdeherança.html

RECEBIDO EM: 19/07/2007

ACEITO EM: 28/05/2008

Endereço para corespondência:

Rua Itaverava, 164 ap. 111B

Guarulhos - SP

CEP: 07111-040

Tel: (11) 2409-8062 / 8957-1705

E-mail: marcela_rosana2@ @otmail.com 